\title{
A New Satisfaction Evaluation Method Based on Fuzzy Clustering
}

\author{
Jingfei Ren ${ }^{1,2}$, Yonghuan $\mathrm{He}^{2}$, Mingming $\mathrm{Hu}^{2}$, Maozhu Jin ${ }^{2, *}$ and Huafeng $\mathrm{Gao}^{2,3}$ \\ ${ }^{1}$ Management Faculty of Chengdu University of Information Technology, China \\ ${ }^{2}$ Business school of Sichuan University, China \\ ${ }^{3}$ Hubei University for Nationalities, China \\ *Corresponding author: jinmaozhu@scu.edu.cn
}

\begin{abstract}
In recent years, the world tourism is developing rapidly. The world tourism firstly hit 1 billion in 2012. Along with the tourism booming, complaint cases are growing and tourists' satisfaction degree is dropping. In this case, to ensure the interests of tourists and keep sustainable development of tourism, the tourists' satisfaction should be evaluated and the Scenic should be improved based on the evaluation result. In this paper, a new tourist satisfaction evaluation method is proposed based on fuzzy clustering. Firstly, the large scale evaluation data is divided to ${ }^{c}$ parts by the fuzzy clustering method. Then, each center of the c parts is chosen to evaluate the tourist satisfaction. The new evaluation method is different from the traditional methods. It can effectively cut the evaluation scale. Finally, the tourist satisfaction of Three Gorges Scenic is studied to interpret the new evaluation method.
\end{abstract}

Keywords: satisfaction evaluation, FCM algorithm, WAA

\section{Introduction}

According to a report released by World Tourism Organization, global tourist arrivals reached 1 billion in 2012, and increased 4\% over the last year under the world economic downturn. It is expected to remain a growth of 3\% to 4\% in 2013. The World Tourism Organization estimated that by 2020 the global tourist arrivals would keep an average annual growth of 3.8\% and would reach 1.8 billion in 2030 [1]. While the tourism is booming, tourists' satisfaction is reduced. The tourists' complaint cases are growing rapidly. Take China for example, the accepted cases increased 35.6\%, from 11060 [2] in 2011 to 15000 in 2012 [3]. Obviously, to guarantee the interests of tourists and keep sustainable development of tourism, it is urgent to evaluate the tourist satisfaction and improve the service in Scenic.

In recent years, many experts and scholars have studied the tourist satisfaction, and adopted a variety of evaluation methods. The tourist satisfaction evaluation method can be divided into two categories: qualitative and quantitative. Qualitative evaluation methods mainly include the commonly used expert method [4], experiential evaluation and aesthetic quality [5], cognitive-affective mode [6]. Quantitative evaluation methods mainly include the analytic hierarchy process [7], fuzzy comprehensive evaluation method [8], grey correlation analysis method [9], tourists' satisfaction index (TSI) evaluation model [10], IPA analysis method [11] triangle fuzzy number of evaluation [12], HOLSAT model [13]. The existing literatures analysis the questionnaire data by the way of analyzing the reliability, completing the incomplete data by the mean of the corresponding attributes and aggregating the evaluation information by arithmetic mean operator. However, different attribute may take different importance in satisfaction evaluation. In this paper, a new evaluation method based on the fuzzy clustering will be introduced, which takes the different attribute weights and different group weights in the aggregation. This paper is organized as follows. In section 2, a new evaluation method based on the Fuzzy $\mathrm{C}$ mean algorithm is introduced. An empirical research is done in section 3 to assess the tourist satisfaction in the Yangtze three gorges scenic. This paper is concluded in Section 4. 


\section{A New Evaluation Method based on the Fuzzy C Mean Algorithm}

In a multi-attribute evaluation problem, let $A=\left\{a_{1}, a_{2}, \cdots, a_{n}\right\}$ be the set of $n$ attributes, $E=\left\{e_{1}, e_{2}, \cdots, e_{m}\right\}$ be the set of $m$ evaluators, $I=\{1,2, \cdots, m\}$ be the index set and $J=\{1,2, \cdots, n\}$ be the index set. Each evaluator $e_{i}$ assesses each attribute ${ }^{a_{j}}$ in A and provides his/her evaluation information ${ }^{y_{i j}}$ in $\{1,2,3,4,5\}$ where 1 means the attribute is very bad, 2 means the attribute is bad, 3 means the attribute is general, 4 means the attribute is good and 5 means the attribute is very good. All evaluators' assess information composes the evaluation matrix $Y=\left(y_{i j}\right)_{m \times n}$.

$$
Y=\left[\begin{array}{llll}
y_{11} & y_{12} & \cdots & y_{1 n} \\
y_{21} & y_{22} & \cdots & y_{2 n} \\
\vdots & \vdots & \vdots & \vdots \\
y_{m 1} & y_{m 2} & \cdots & y_{m n}
\end{array}\right]
$$

\subsection{Cluster the Evaluation Information by Fuzzy C Mean Algorithm}

Fuzzy C means algorithm is a partitioned clustering method. In literature [14], it introduces the concept of hard $\mathrm{C}$ partition and then introduces fuzzy $\mathrm{C}$ partition by extending the membership functions between samples and the class. In the following part, we will review fuzzy $\mathrm{C}$ mean algorithm introduced in literature [14].

Suppose $Y=\left\{y_{1}, y_{2}, \cdots, y_{m}\right\}$ is a sample space, where $y_{i}=\left(y_{i 1}, y_{i 2}, \cdots, y_{i n}\right) \in R^{n}(i \in I)$, $Y_{1}, Y_{2}, \cdots, Y_{c}$ are $c$ subsets of $Y_{\text {and }} K=\{1,2, \cdots, c\}$. If $Y_{1}, Y_{2}, \cdots, Y_{c}$ satisfy:

$$
\begin{aligned}
& Y_{1} \cup Y_{2} \cup \cdots \cup Y_{c}=Y, \\
& Y_{i} \cap Y_{j}=\varnothing, \quad i, j \in \text { Kand } i \neq j, \\
& Y_{i} \neq \varnothing, Y_{i} \neq Y, i \in K .
\end{aligned}
$$

We say $Y_{1}, Y_{2}, \cdots, Y_{c}$ is hard $\mathrm{C}$ partition of $Y$.

Suppose

$$
U=\left(u_{h i}\right)_{c \times m}=\left[\begin{array}{cccc}
y_{1} & y_{2} & \cdots & y_{m} \\
u_{11} & u_{12} & \cdots & u_{1 m} \\
u_{21} & u_{22} & \cdots & u_{2 m} \\
\vdots & \vdots & \vdots & \vdots \\
u_{c 1} & u_{c 2} & \cdots & u_{c m}
\end{array}\right] \begin{gathered}
Y_{1} \\
Y_{2} \\
\vdots \\
Y_{c}
\end{gathered}
$$

is the hard $\mathrm{C}$ partition matrix of $\mathrm{Y}$, where $u_{Y_{k}}\left(y_{i}\right)(i \in I, k \in K)$ indicates the subordinate relations between sample $y_{i}(i \in I)$ and subset $Y_{k}(k \in K)$. It is obviously that $u_{k i} \in\{0,1\}$, $u_{k i}=1$ means that $y_{i}$ only belongs to subset $Y_{h}$ while $u_{k i}=0$ means that $y_{k}$ does not belong to subset $Y_{h}$.

Definition 1 [14] Suppose $R^{c \times m}$ is a $c \times m$ real matrix space. Consider the sample data set $Y=\left\{y_{1}, y_{2}, \cdots, y_{m}\right\}$ and integer $c(2 \leq c \leq m)$, then the hard $\mathrm{C}$ partition matrix of $Y$ is :

$$
\begin{aligned}
& M_{c}=\left\{U \in R^{c \times m} \mid u_{k i} \in\{0,1\}, \forall k \in K, i \in I ;\right. \\
& \left.\sum_{k=1}^{c} u_{k i}=1, \forall i \in I ; 0<\sum_{i=1}^{m} u_{k i}<m, \forall k \in K\right\}
\end{aligned}
$$

In fact, A sample is not always belongs to a particular class, it may also belong to other 
classes. Therefore, literature [15] extend subordinate relations between the samples and the class of hard $\mathrm{C}$ partition and obtain fuzzy $\mathrm{C}$ partition space.

Definition $2[14,15] \quad$ suppose $A^{c \times m}$ represents $c \times m$ order real matrix space in the real number field. Consider the sample data set $Y=\left\{y_{1}, y_{2}, \cdots, y_{m}\right\}$ and integer $c(2 \leq c \leq m)$, then the fuzzy $\mathrm{C}$ partition space of $Y$ is:

$$
\begin{aligned}
& M_{f c}=\left\{U \in R^{c \times m} \mid 0 \leq u_{k i} \leq 1, \forall k \in K, i \in I ;\right. \\
& \left.\sum_{k=1}^{c} u_{k i}=1, \forall i \in I ; 0<\sum_{i=1}^{m} u_{k i}<m, \forall k \in K\right\}
\end{aligned}
$$

Suppose $V=\left\{v_{1}, v_{2}, \cdots, v_{c}\right\}$ is the clustering prototype of $Y_{k}(k \in K)$, in which $v_{k} \in R^{n}(k \in K)$.According to literature [14] and literature [15], we can solve the optimization model:

$$
\begin{gathered}
(\mathrm{M}-1) \quad \min \quad J(U, V)=\sum_{k=1}^{m} \sum_{h=1}^{c}\left(u_{h k}\right)^{s}\left\|y_{k}-v_{h}\right\|^{2} \\
\text { s.t. } \sum_{h=1}^{c} u_{h k}=1, \quad \forall k=1,2, \cdots, m
\end{gathered}
$$

where $s$ is parameter controls the fuzzy degree of membership function $u_{k i}=u_{Y_{k}}\left(y_{i}\right)$. It is usually set to 2 . The problem can be solved by the Lagrange Multiplier Method, the results are as follows.

\section{Algorithm 1 [15]}

$$
\begin{aligned}
\left(u_{k i}\right)^{-1} & =\sum_{h=1}^{c}\left(\frac{\left\|y_{i}-v_{k}\right\|}{\left\|y_{i}-v_{h}\right\|}\right)^{2 /(s-1)}, \forall k \in K, i \in I . \\
v_{k} & =\frac{\sum_{i=1}^{n}\left(u_{k i}\right)^{s} y_{i}}{\sum_{i=1}^{n}\left(u_{k i}\right)^{s}}, \forall k \in K .
\end{aligned}
$$

Input: $Y=\left\{y_{1}, y_{2}, \cdots, y_{m}\right\}$, the clustering number parameter $c(2 \leq c \leq m)$,parameter $s$ and the termination threshold $\varepsilon$.

Output:The partition matrix $\mathrm{U}$ and the clustering prototype $\mathrm{V}$.

Step1: Input $Y=\left\{y_{1}, y_{2}, \cdots, y_{m}\right\}$, the clustering number parameter $c(2 \leq c \leq m)$,parameter $s$ and the termination threshold $\varepsilon$.

Step2: Initialize partition matrix $U^{(0)}=\left(u_{k i}^{(0)}\right)_{c \times m}$ randomly and $U^{(0)}$ satisfies equation (3). Set the initialized loopcounter $t=0$.

Step3: Update the clustering prototype $V^{(t)}=\left\{v_{1}^{(t)}, v_{2}^{(t)}, \cdots, v_{c}^{(t)}\right\}$ by

$$
v_{k}^{(t)}=\frac{\sum_{i=1}^{n}\left(u_{k i}^{(t)}\right)^{s} y_{i}}{\sum_{i=1}^{n}\left(u_{k i}^{(t)}\right)^{s}}, \forall k \in K .
$$

Step4: Update partition matrix $U^{(t+1)}=\left(u_{h k}^{(t+1)}\right)_{c \times m}$ by

$$
\left(u_{k i}^{(t+1)}\right)^{-1}=\sum_{h=1}^{c}\left(\| \frac{y_{i}-v_{k}^{(t)} \|}{\left\|y_{i}-v_{h}^{(t)}\right\|}\right)^{2 /(s-1)}, \forall k \in K, i \in I .
$$

Step5: If $\left\|U^{(t)}-U^{(t+1)}\right\| \leq \varepsilon$, then output the partition matrix $U$ and the clustering prototypeV and stop. Otherwise, let $t=t+1$ and go to Step3. 
By Algorithm 1, the evaluation information $Y=\left(y_{1}, y_{2}, \cdots, y_{m}\right)^{T}$ provided by all evaluators is divided to $\mathrm{C}$ groups $Y_{1}, Y_{2}, \cdots, Y_{c}$, whose clustering prototype is $v_{1}, v_{2}, \cdots, v_{c}$. Each clustering prototype ${ }^{v_{k}}$ stands for the group $Y_{k}$. In this way, all the evaluation information can be simplified to the group evaluation information $V=\left(v_{k j}\right)_{c \times n}$.

$$
V=\left(v_{k j}\right)_{c \times n}=\left(\begin{array}{l}
v_{1} \\
v_{2} \\
\vdots \\
v_{c}
\end{array}\right)=\left[\begin{array}{l}
v_{11} v_{12} \cdots v_{1 n} \\
v_{21} v_{22} \cdots v_{2 n} \\
\vdots \\
v_{c 1} v_{c 2} \cdots v_{c n}
\end{array}\right]
$$

\subsection{Generate the Groups' Weight and Attributes' Weight}

To aggregate all the group evaluation information in Eq.(9), two kinds of weights should be generated. The first one is the weight $W_{Y}=\left(\omega^{1}, \omega^{2}, \cdots, \omega^{c}\right)^{T}$ of $\mathrm{C}$ group, where $\sum_{k=1}^{c} \omega^{k}=1$ and $\omega^{k}>0$. Another is the weight $W_{A}=\left(\omega_{1}, \omega_{2}, \cdots, \omega_{n}\right)^{T}$ of $\mathrm{n}$ attributes, where $\sum_{j=1}^{n} \omega^{j}=1$ and $\omega^{j}>0$.In the following part, we will generate the two kinds of weights.

- Generate the groups' weight

In the groups' weight $W_{Y}=\left(\omega^{1}, \omega^{2}, \cdots, \omega^{c}\right)^{T}$, the number of $\omega^{k}$ stands for the importance of the group $Y_{k}$. From Algorithm 1, the partition matrix $U=\left(u_{h i}\right)_{c \times m}$ will be output:

$$
U=\left(u_{h i}\right)_{c \times m}=\left[\begin{array}{cccc}
y_{1} & y_{2} & \cdots & y_{m} \\
u_{11} & u_{12} & \cdots & u_{1 m} \\
u_{21} & u_{22} & \cdots & u_{2 m} \\
\vdots & \vdots & \vdots & \vdots \\
u_{c 1} & u_{c 2} & \cdots & u_{c m}
\end{array}\right] \begin{gathered}
Y_{1} \\
Y_{2} \\
\vdots \\
Y_{c}
\end{gathered}
$$

where $u_{k i}=u_{Y_{k}}\left(y_{i}\right)(i \in I, k \in K)$ indicates the degree of sample $y_{i}(i \in I)$ belonging to group $Y_{k}(k \in K)$. Considering a vote model, $u_{k i}$ can be regarded as the turnout that $y_{i}(i \in I)$ vote group ${ }^{Y_{k}(k \in K)}$. Taking the idea of Lijphart[16] that higher turnout rates reflects greater representation of the entire populace, the weight $\omega^{k}$ of group ${ }^{Y_{k}}$ can be calculated by the turnout rates that

$$
\omega^{k}=\frac{\sum_{i=1}^{n} u_{k i}}{n}, \forall k \in K .
$$

- Generate the attributes' weight

Generating the attributes' weight is a hot topic in multi-attribute decision making, there are several methods to generate the attributes' weight. All these methods can be divided to three classes: subjectively weight method (Least Square method, Delphi method, Analytic Hierarchy Process (AHP) method, Binomial Coefficient method), objectively weight method(Principal Component Analysis (PCA), Entropy method, Multi-objective programming method, Standard Deviation method) and combination weight method. In this 
paper, an objectively weight method proposed by Diakoulaki, et al., [17] will be taken to generate the attributes' weight. $V=\left(v_{k i}\right)_{c \times n}$ is the evaluation matrix and $W_{A}=\left(\omega_{1}, \omega_{2}, \cdots, \omega_{n}\right)^{T}$ is the weight vector of attributes. Then the weight of the $\$$ i\$th attribute can be calculated by

$$
\omega_{i}=\frac{\sigma_{i}}{\sum_{h=1}^{n} \sigma_{h}}, i \in I,
$$

where

$$
\sigma_{j}=\sqrt{\frac{1}{c} \sum_{k=1}^{c}\left(v_{k i}-\frac{1}{c} \sum_{k=1}^{c} v_{k i}\right)^{2}}
$$

is the standard deviation of ith attribute evaluation data among the evaluation matrix.

The group weight $W_{Y}=\left(\omega^{1}, \omega^{2}, \cdots, \omega^{c}\right)^{T}$ and the attribute weight $W_{A}=\left(\omega_{1}, \omega_{2}, \cdots, \omega_{n}\right)^{T}$ can be calculated by Eq.(11) and Eq.(12) respectively. Based on the group weight and attribute weight, an aggregating method will be introduced in the next part.

\subsection{Aggregate the Evaluation Information}

Many authors' have made some efforts on the aggregating method. For example, the arithmetic mean, the weighted arithmetic mean, the quadratic mean and the harmonic mean is firstly proposed as a kind of aggregating method [18]. Furthermore, Yager [19] proposed the ordered weighted averaging (OWA) operator in 1988. Then, the OWA operator is extended to different kinds of aggregating operators in different study environments, such as the ordered weighted geometric averaging (OWGA) operator[20,21], the linguistic weighted ordered weighted averaging (LOWA) operator [22, 23], the linguistic ordered weighted geometric averaging (LOWGA) operator [24], the induced ordered weighted averaging (IOWA) operators [25], the induced ordered weighted geometric averaging (IOWGA) operators[26], the weighted ordered weighted averaging (WOWA) operator [27], the generalized weighted ordered weighted averaging(GOWA) operator [28], the induced generalized ordered weighted averaging (IGOWA) operator [29], the uncertain induced heavy ordered weighted averaging (UIHOWA) operator [30], the induced ordered weighted averaging weighted average (IOWAWA) operator [31], the induced linguistic generalized ordered weighted averaging(ILGOWA) operator [32], the linguistic generalized ordered weighted averaging (LGOWA) operator [33], the continuous generalized ordered weighted averaging (C-GOWA) operator [34], the uncertain generalized ordered weighted averaging (UGOWA) operator [35], the generalized power ordered weighted average (GPOWA) operator and the linguistic generalized power ordered weighted average (LGPOWA) operator [36], the induced uncertain linguistic ordered weighted averaging (IULOWA) operator [37], a dependent uncertain ordered weighed aggregation (DUOWA) operator[38].

In this paper, considering the different weights of attributes, the weighted arithmetic mean method[18] is taken to aggregate the information in different attributes.

Definition 3 Suppose WAA: $R^{n} \rightarrow R$ and $W=\left(\omega_{1}, \omega_{2}, \cdots, \omega_{n}\right)^{T}$ is the weight vector of data set $\left(\alpha_{1}, \alpha_{2}, \cdots, \alpha_{n}\right)^{T}$. Then, $\left(\alpha_{1}, \alpha_{2}, \cdots, \alpha_{n}\right)^{T}$ can be aggregated by

$$
\mathrm{WAA}_{w}\left(\alpha_{1}, \alpha_{2}, \ldots, \alpha_{n}\right)=\sum_{j=1}^{n} w_{j} \alpha_{j},
$$

which is called the weighted arithmetic mean(WAA) operator.

Based on the aggregating operator in Definition 3, there are two stages to aggregate the group evaluation information in $V=\left(v_{k i}\right)_{c \times n}$.

- Aggregate the groups' evaluation information in each attribute 
$V=\left(v_{k i}\right)_{c \times n}$ is the group evaluation information matrix, where $v_{k i}$ indicates the evaluation information of ${ }^{a_{j}}$ evaluated by group $Y_{k}, W_{Y}=\left(\omega^{1}, \omega^{2}, \cdots, \omega^{c}\right)^{T}$ is the group weight vector, where $\omega^{k}$ indicates the importance of the kth group. Suppose $A E V=\left(a e v_{1}, a e v_{2}, \cdots, a e v_{n}\right)^{T}$ is the attribute evaluation value(AEV) vector. By Definition 3 , the group evaluation information can be aggregated to the AEV that

$$
a e v_{j}=\sum_{k=1}^{c} v_{k j} \cdot \omega^{k}, j \in J \text {. }
$$

With Eq.(14), the attribute evaluation value (AEV) vector

$$
A E V=\left(a e v_{1}, a e v_{2}, \cdots, a e v_{n}\right)^{T}
$$

can be calculated, and the AEV will be aggregated in the next part.

- Aggregate the attribute evaluation information

$A E V=\left(\operatorname{aev}_{1}, a e v_{2}, \cdots, a e v_{n}\right)^{T}$ is the attribute evaluation value(AEV) vector, where $a e v_{j}$ indicates the evaluation value of the jth attribute ${ }^{a_{j}}$.

$W=\left(\omega_{1}, \omega_{2}, \cdots, \omega_{n}\right)^{T}$ is the attribute weight vector, where ${ }^{\omega_{j}}$ indicates the importance of the jth attribute $a_{j}$. By Definition 3, the overall evaluation value(OEV) can be generated by

$$
O E V=\sum_{j=1}^{n} a e v_{j} \cdot \omega_{j}
$$

\subsection{The Evaluation Process}

Based on the discussion above, the evaluation process can be summarized as follows.

Step 1: Pretreat the evaluation information and get the evaluation matrix $Y=\left(y_{1}, y_{2}, \cdots, y_{m}\right)^{T}=\left(y_{i j}\right)_{m \times n}$.

Step 2: Divide the evaluation information $Y=\left(y_{1}, y_{2}, \cdots, y_{m}\right)^{T}$ into $\mathrm{C}$ groups $Y_{1}, Y_{2}, \cdots, Y_{c}$ by Algorithm 1 and get the partition matrix $\mathrm{U}$ and the group evaluation information matrix V.

Step 3: Generate the groups' weight $W_{Y}=\left(\omega^{1}, \omega^{2}, \cdots, \omega^{c}\right)^{T}$ by Eq.(11), according to the partition matrix U. And generate the attributes' weight $W_{A}=\left(\omega_{1}, \omega_{2}, \cdots, \omega_{n}\right)^{T}$ by Eq.(12).

Step 4: Aggregate the attribute evaluation value (AEV) vector $A E V=\left(a e v_{1}, a e v_{2}, \cdots, a e v_{n}\right)^{T}$ by Eq.(14). And aggregate the overall evaluation value (OEV) by Eq.(15).

Step 5: Make some advice according to the overall evaluation value (OEV) and the attribute evaluation value (AEV).

An empirical research will be introduced in the next part to interpret the evaluation process.

\section{A Tourist Satisfaction Empirical Research}

A tourist satisfaction survey is taken in the Yangtze three gorges scenic in China, which is named as the key scenic spot in 1982 by the State Council of China. It consists of fengjie-treasure, qutang gorge, wu gorge, shennv creek, small three gorges, dacang town, wuxi temple gorge, natural ecological cultivation area, zhongxian marvel, video mountains, fulling built, and so on. According to the characters of the Yangtze three gorges scenic, we 
designed a satisfaction questionnaire with the corresponding relationships between scoring value and satisfaction in this questionnaire is as follows: 1 - very dissatisfied, 2 - dissatisfied, 3 - general , 4 - satisfied, 5 - very satisfied. And 200 tourists were randomly selected in this scenic taking the query-answer mode. Then we got the 200 tourists' satisfaction evaluation information.

Now, we can complete the satisfaction evaluation as the evaluation process shown above.

Step 1: Pretreat the evaluation information.

Remove some questionnaires whose integrity is less than $60 \%$. There are 173 questionnaires left. Then, complete the deformity data by the average mean of the evaluation information of the corresponding attribute and get the evaluation sample information $Y=\left(y_{1}, y_{2}, \cdots, y_{173}\right)^{T}$.

Step 2: Divide the evaluation information $Y=\left(y_{1}, y_{2}, \cdots, y_{173}\right)^{T}$ into 6 groups $Y_{1}, Y_{2}, \cdots, Y_{c}$ by Algorithm 1.

According to the Algorithm 1.

Input: $Y=\left\{y_{1}, y_{2}, \cdots, y_{173}\right\}$, the clustering parameter $\mathrm{c}=6$, parameter $\mathrm{s}=2$ and the termination threshold $\varepsilon=0.01$.

Output: The partition matrix $U=\left(u_{h k}\right)_{6 \times 173}$ and the group evaluation information $V=\left(v_{i j}\right)_{6 \times 34}$ (Table 1).

Step 3: Generate the groups' weight $W_{Y}=\left(w^{1}, w^{2}, \cdots, w^{c}\right)^{T}$ by Eq.(11) (Table 1), according to the partition matrix U. And generate the attributes' weight $W_{A}=\left(w_{1}, w_{2}, \cdots, w_{n}\right)^{T}$ by Eq.(12) (Table 1).

Step 4: Aggregate the attribute evaluation value (AEV) vector $A E V=\left(a e v_{1}, a e v_{2}, \cdots, a e v_{n}\right)^{T}$ by Eq.(14)(Table 1). And aggregate the overall evaluation value (OEV) by Eq.(15)(Table 1).

Step 5: Make some advice according to the overall evaluation value (OEV) and the attribute evaluation value (AEV).

As can be seen from Table 1, the overall evaluation value (OEV) is 2.7746 , which is below the general level. It shows that tourists are not satisfied with this scenic. There are many attributes need to be improved. From the attribute evaluation value (AEV) in Table 1, we can see that only Natural scenery is above the satisfaction level. Almost a half indicators are in a general to satisfied level, which need to be further improved, such as Historical and cultural heritage, Passenger flow moderate degree, Local residents enthusiasm degree, Environmental sanitation, Trash, Public toilets, Public resting facility, Guiding marker, Safety facility, Convenience degree, Scenic routing arrangement, Interpreting service, Shopping environment A big half indicators are in a dissatisfied to general level, which should be improved urgently, such as Ticket price, The degree of information, Transportation price, Tourist complaint, Ticketing service, Consulting service, Restaurant feature, Dining convenience, Food hygiene, Meal price, Accommodation hygiene, Accommodation comfort, Accommodation price, Types of projects, Entertainment, Security, Entertainment price, Types of goods, Shopping feature, Shopping price. Improvement of these indicators will effectively increase the overall satisfaction of the scenic. 
Table 1. The Attribute Evaluation Value and the Overall Evaluation Value

\begin{tabular}{|c|c|c|c|c|c|c|c|c|}
\hline $\begin{array}{l}\text { Index } \\
w^{k}\end{array}$ & $\begin{array}{c}v_{1} \\
0.1668\end{array}$ & $\begin{array}{c}v_{2} \\
0.1663\end{array}$ & $\begin{array}{c}v_{3} \\
0.1668\end{array}$ & $\begin{array}{c}v_{4} \\
0.1666\end{array}$ & $\begin{array}{c}v_{5} \\
0.1664\end{array}$ & $\begin{array}{c}v_{6} \\
0.1670\end{array}$ & $w_{i}$ & $\mathrm{AEV}$ \\
\hline Natural scenery & 4.0759 & 4.0737 & 4.0758 & 4.0748 & 4.0741 & 4.0766 & 0.0033 & 4.0751 \\
\hline Historical and cultural heritage & 3.7082 & 3.6991 & 3.7079 & 3.7039 & 3.7007 & 3.7114 & 0.0137 & 3.7052 \\
\hline Ticket price & 2.9945 & 2.9762 & 2.9938 & 2.9859 & 2.9794 & 3.0007 & 0.0272 & 2.9884 \\
\hline Passenger flow moderate degree & 3.4249 & 3.4160 & 3.4246 & 3.4207 & 3.4176 & 3.4279 & 0.0132 & 3.422 \\
\hline Local residents enthusiasm degree & 3.6625 & 3.6518 & 3.6621 & 3.6575 & 3.6537 & 3.6661 & 0.0160 & 3.659 \\
\hline Environmental sanitation & 3.7885 & 3.7814 & 3.7882 & 3.7851 & 3.7826 & 3.7909 & 0.0106 & 3.7861 \\
\hline Trash & 3.4244 & 3.4170 & 3.4242 & 3.4209 & 3.4183 & 3.4270 & 0.0112 & 3.422 \\
\hline Public toilet & 3.0591 & 3.0378 & 3.0584 & 3.0490 & 3.0415 & 3.0664 & 0.0319 & 3.052 \\
\hline Public resting facility & 3.2657 & 3.2488 & 3.2651 & 3.2577 & 3.2517 & 3.2716 & 0.0254 & 3.2601 \\
\hline Guiding marker & 3.4030 & 3.3904 & 3.4026 & 3.3971 & 3.3926 & 3.4074 & 0.0189 & 3.3988 \\
\hline Safety facility & 3.5746 & 3.5676 & 3.5743 & 3.5712 & 3.5688 & 3.5771 & 0.0105 & 3.5723 \\
\hline The degree of information & 2.7190 & 2.6948 & 2.7182 & 2.7076 & 2.6990 & 2.7274 & 0.0364 & 2.711 \\
\hline Convenience degree & 3.5057 & 3.4972 & 3.5054 & 3.5016 & 3.4986 & 3.5088 & 0.0129 & 3.5029 \\
\hline Scenic routing arrangement & 3.4377 & 3.4251 & 3.4373 & 3.4317 & 3.4273 & 3.4421 & 0.0189 & 3.4335 \\
\hline Transportation & 2.0193 & 1.9784 & 2.0179 & 2.0000 & 1.9855 & 2.0334 & 0.0613 & 2.0058 \\
\hline Tourist complaint & 2.2895 & 2.2530 & 2.2883 & 2.2723 & 2.2594 & 2.3021 & 0.0548 & 2.2775 \\
\hline Interpreting service & 3.6690 & 3.6561 & 3.6686 & 3.6629 & 3.6583 & 3.6735 & 0.0194 & 3.6647 \\
\hline Ticketing service & 2.6233 & 2.5912 & 2.6223 & 2.6082 & 2.5968 & 2.6344 & 0.0481 & 2.6127 \\
\hline Consulting service & 3.0025 & 2.9776 & 3.0016 & 2.9907 & 2.9819 & 3.0111 & 0.0374 & 2.9942 \\
\hline Restaurant feature & 2.8056 & 2.7816 & 2.8048 & 2.7944 & 2.7858 & 2.8137 & 0.0359 & 2.7977 \\
\hline Dining ce & 2.9833 & 2.9638 & 2.9827 & 2.9742 & 2.9672 & 2.9900 & 0.0292 & 2.9769 \\
\hline Food hygiene & 2.8401 & 2.8166 & 2.8393 & 2.8291 & 2.8208 & 2.8481 & 0.0351 & 2.8324 \\
\hline Meal price & 2.5886 & 2.5565 & 2.5876 & 2.5736 & 2.5622 & 2.5995 & 0.0479 & 2.578 \\
\hline Accommodation hygiene & 2.7596 & 2.7348 & 2.7588 & 2.7480 & 2.7392 & 2.7680 & 0.0370 & 2.7514 \\
\hline Accommodation comfort & 2.8096 & 2.7911 & 2.8090 & 2.8009 & 2.7943 & 2.8159 & 0.0276 & 2.8035 \\
\hline Accommodation price & 2.2418 & 2.2097 & 2.2408 & 2.2268 & 2.2153 & 2.2528 & 0.0481 & 2.2312 \\
\hline Types of projects & 2.3625 & 2.3325 & 2.3615 & 2.3485 & 2.3378 & 2.3727 & 0.0448 & 2.3526 \\
\hline Entertainment & 2.6272 & 2.6009 & 2.6263 & 2.6149 & 2.6055 & 2.6361 & 0.0393 & 2.6185 \\
\hline Security & 2.6686 & 2.6394 & 2.6676 & 2.6550 & 2.6445 & 2.6785 & 0.0436 & 2.659 \\
\hline Entertainment price & 2.2703 & 2.2394 & 2.2693 & 2.2559 & 2.2448 & 2.2808 & 0.0462 & 2.2601 \\
\hline Types of goods & 2.9245 & 2.9081 & 2.9239 & 2.9168 & 2.9110 & 2.9301 & 0.0245 & 2.9191 \\
\hline Shopping environment & 3.0153 & 3.0040 & 3.0149 & 3.0100 & 3.0060 & 3.0192 & 0.0169 & 3.0116 \\
\hline Shopping feature & 2.8895 & 2.8740 & 2.8890 & 2.8822 & 2.8767 & 2.8949 & 0.0232 & 2.8844 \\
\hline Shopping price & 2.7811 & 2.7614 & 2.7804 & 2.7718 & 2.7648 & 2.7878 & 0.0295 & 2.7746 \\
\hline $\mathrm{OEV}$ & & & & & & & & 2.7717 \\
\hline
\end{tabular}

\section{Conclusions}

A new evaluation method based on fuzzy clustering is proposed and an empirical research is done in the survey of tourist satisfaction in the Yangtze three gorges scenic in China. In this paper, the fuzzy c mean algorithm (Algorithm 1) is introduced to divide the evaluation sample $Y=\left\{y_{1}, y_{2}, \cdots, y_{m}\right\}$ into $\mathrm{C}$ groups $Y_{1}, Y_{2}, \cdots, Y_{c}$ and get the partition matrix $\mathrm{U}$ as well as the clustering prototype $\mathrm{V}$. The partition matrix $U=\left(u_{k i}\right)_{c \times m}$ is taken to generate the groups' weight by considering the vote model [19]. The clustering prototype $V=\left(v_{k j}\right)_{c \times n}$ is taken as the group evaluation information. In this case, standard deviation method proposed by Diakoulaki, et al., [17] is taken to generate the attributes' weight. Furthermore, the weighted arithmetic mean (WAA) [18] operator is taken to aggregate the attribute evaluation value (AEV) and the overall evaluation value (OEV). Finally, an empirical research is done to investigate the tourist satisfaction in the Yangtze three gorges scenic by the new proposed method. The result shows that the overall evaluation value is below the general level. Many attributes are urgent to be improved in order to reverse the tourist satisfaction situation, such as Ticket price, The degree of information, Transportation price, Tourist complaint, Ticketing service, Consulting service, Restaurant feature, Dining convenience, Food hygiene, Meal price, Accommodation hygiene, Accommodation comfort, Accommodation price, Types of projects, Entertainment, Security, Entertainment price, Types of goods, Shopping feature, 
Shopping price and so on.

\section{Acknowledgements}

This research was supported by the National Natural Science Foundation of China (Nos. 71001075, 71261001, 71371130 and 71302134), the Major International Joint Research Program of the National Natural Science Foundation of China(No.71020107027), the Major Social Science Foundation of Chengdu (SKNHR13-07), the Postdoctoral Foundation of China (2012M521704), the key issue from the ethnic affairs in Hubei province (HBMW2013008) and Doctoral Foundation of Ministry of Education of China (20110181110034).

\section{References}

[1] J. Dai, "Global tourist arrivals in 2012 hit the 1 billion mark for the first time", Retrieved from, (2013), http://travel.cnwest.com/content/2013-01/31/content_8413050.htm.

[2] "National Tourism briefing", Retrieved from, (2011), http://www.cnta.gov. $\mathrm{cn} / \mathrm{html} / 2012-3 / 2012-3-26-15-24-39795 . h t m l$.

[3] "China national tourism administration releases the government information disclosure work report in 2012", Retrieved from, (2013), http://www. gov.cn/gzdt/2013-03/28/content_2364427.htm.

[4] H. Li, Y. Cheng, "Scenic area planning and evaluation of Yalu River scenic area", Journal of Dandong Teachers College, vol. 3, (1996).

[5] Y. Niu, "The building of Tourism scenic spot evaluation model and its application", Henan Zhengzhou University, (2007).

[6] I. R. Bosque and H. S. Martín, "Tourist satisfaction a cognitive-affective model", Annals of Tourism Research, vol. 35, (2008).

[7] J. Wang, "Intelligent Transportation Systems Deployment Study and Evaluation for the Jiuzhaigou Valley Management", Sichuan Southwestern university of finance and economics, (2007).

[8] Q. Zhang, "An Empirical Study on Tourist Satisfaction in the Baishuiyang Resort", Ningde World Geological Park in Fujian. Fujian normal university. Fujian, (2012).

[9] J. Nan and W. Li, "A Study on Evaluation of Tourist Satisfaction Degree Based on Gray System Theory", Commercial Research, vol. 12, (2008).

[10] Q. Wang, Z. Ding, J. Zhang and X. Yang, "Study on the model of tourist satisfaction index about tourism environment: a case study of Huangshan Mountain", Geographical Research, vol. 25, (2006).

[11] C. Cai, P. Lan, C. Tang and X. Zhang, "Evaluation of Tourists' Satisfaction Degree of Folk House World Heritages Based on IPA Analysis: A Case Study of Yongding Hakka Earth Building in Fujian Province, China", Resource Science, vol. 33, (2011).

[12] X. Yang, "Research on the Evaluation of Tourist Satisfaction Based on Triangular Fuzzy Number", Jiangxi normal University, Jiangxi, (2012).

[13] T. Truong and D. Foster, "Using HOLSAT to evaluate tourist satisfaction at destinations: The case of Australian holiday makers in Vietnam", Tourism Management, vol. 27, (2006)

[14] J. C. Bezdek, "Pattern Recogition with Fuzzy Objective Function Algorithms. Norwell", MA, USA: Kluwer Academic Publishers, (1981)

[15] M. Filippone, F. Aamastra, F. Masulli and S. Rovetta, "A survey on kernel and spectral methods for clustering", Pattern Recognition, vol. 41, (2008).

[16] A. Lijphart, "Unequal participation: democracy's unresolved dilemma", American Political Science Review, vol. 91, (1997).

[17] D. Diakoulaki, G. Mavrotas and L. Papayannakis, "Determining objective weights in multiple criteria problems", The critic method. Computers $\backslash \&$ Operations Research, vol. 22, (1995).

[18] "mean", Encyclopdia Britannica. Encyclopdia Britannica Online Academic Edition, Retrieved from, (2013), lurl\{http://www.britannica.com/EBchecked/topic/371524/mean \}.

[19] R. R. Yager, "On ordered weighted averaging aggregation operators in multi criteria decision making", IEEE Transactions on Systems, Man, and Cybernetics, vol. 18, (1988)

[20] F. Chiclana, F. Herrera and E. Herrera-Viedma, "Integrating multiplicative preference relations in a multipurpose decision making model based on fuzzy preference relation”, Fuzzy Sets and Systems, vol. 122, (2001).

[21] Z. S. Xu and Q. L. Da, "The ordered weighted geometric averaging operators", International Journal of Intelligent Systems, vol. 17, (2002).

[22] F. Herrera, "A sequential selection process in group decision making with linguistic assessment", Information Sciences, vol. 85, (1995).

[23] F. Herrera and L. Martínez, "A 2-tuple fuzzy linguistic representation model for computing with words", IEEE Transactions on Fuzzy Systems, vol. 8, (2000).

[24] Z. S. Xu, "A method based on linguistic aggregation operators for group decision making with linguistic 
preference relations", Information Sciences, vol. 166, (2004).

[25] R. R. Yager and D. P. Filev, "Induced ordered weighted averaging operators", IEEE Transactions on Systems, Man, and Cybernetics, vol. 29, (1999).

[26] Z. S. Xu and Q. L. Da, “An overview of operators for aggregating information”, International Journal of Intelligent Systems, vol. 18, (2003).

[27] V. Torra, "The weighted OWA operator", International Journal of Intelligent Systems, vol. 12, (1997).

[28] P. A. Schaefer and H. B. Mitchell, “A generalized OWA operator”, International Journal of Intelligent Systems, vol. 14, (1999).

[29] J. M. Merigó and A. M. Gil-Lafuente, "The induced generalized OWA operator. Information Sciences", vol. 179, (2009).

[30] J. M. Merigó and M. Casanovas, "Induced and uncertain heavy OWA operators", Computers and Industrial Engineering, vol. 60, (2011).

[31] J. M. Merigó, "A unified model between the weighted average and the induced OWA operator", Expert Systems with Applications, vol. 38, (2011).

[32] J. M. Merigó, A. M. Gil-Lafuente, L. G.Zhou and H. Y. Chen, "Induced and linguistic generalized aggregation operators and their application in linguistic group decision making", Group Decision and Negotiation, vol. 21, (2012).

[33] J. M. Merigó, A. M. Gil-Lafuente, L. G. Zhou and H. Y. Chen, "Generalization of the linguistic aggregation operator and its application in decision making", Journal of Systems Engineering and Electronics, vol. 22, (2011).

[34] L. G. Zhou and H. Y. Chen, "Continuous generalized OWA operator and its application to decision making”, Fuzzy Sets and Systems, vol. 168, (2011).

[35] L. G. Zhou, H. Y. Chen, J. M. Merigó and A. M. Gil-Lafuente, "Uncertain generalized aggregation operators", Expert Systems with Applications, vol. 39, (2012).

[36] L. G. Zhou and H. Y. Chen, "A generalization of the power aggregation operators for linguistic environment and its application in group decision making", Knowledge-Based Systems, vol. 26, (2012).

[37] Z. S. Xu, "Induced uncertain linguistic OWA operators applied to group decision making", Information Fusion, vol. 7, (2006).

[38] Z. S. Xu, "Dependent uncertain ordered weighted aggregation operators", Information Fusion, vol. 9, (2008). 